\title{
Mulemba
}

Revista Angolana de Ciências Sociais

4 (8) | 2014

Globalização, gestão e dinâmicas de desenvolvimento regional e local

\section{A estratégia de participação para a educação no valor participação social para o desenvolvimento comunitário no Bairro Benvindo em Luanda, Angola}

Participation strategy for education for the value of social participation and for community development in the Benvindo neighborhood, Luanda, Angola

Maria Adelina Lima do Nascimento Alberto

\section{(2) OpenEdition}

Edição electrónica

URL: http://journals.openedition.org/mulemba/288

DOI: $10.4000 /$ mulemba.288

ISSN: 2520-0305

Editora

Edições Pedago

\section{Edição impressa}

Data de publição: 1 novembro 2014

Paginação: 203-239

ISSN: 2182-6471

\section{Refêrencia eletrónica}

Maria Adelina Lima do Nascimento Alberto, «A estratégia de participação para a educação no valor participação social para o desenvolvimento comunitário no Bairro Benvindo em Luanda, Angola», Mulemba [Online], 4 (8) | 2014, posto online no dia 28 novembro 2016, consultado o 27 janeiro 2021 URL: http://journals.openedition.org/mulemba/288 ; DOI: https://doi.org/10.4000/mulemba.288 


\section{A estratégia de participação para a educação no valor participação social para o desenvolvimento comunitário no Bairro Benvindo em Luanda, Angola}

Participation strategy for education for the value of social participation and for community development in the Benvindo neighborhood, Luanda, Angola

Maria Adelina Lima do Nascimento Alberto

\section{NOTA DO EDITOR}

Artigo solicitado a Autora

Recepção do manuscrito: 16/10/2014

Conclusão da revisão: 8/12/2014

Aceite para publicação: 30/12/2014

\section{NOTA DO AUTOR}

Este artigo constitui uma síntese que resulta da minha tese de doutoramento em Ciências Pedagógicas, orientada pela Prof. Doutora Mercedas Cristina Gutierrez Mazorra da Universidade de Ciências Pedagógicas Enrique José Varona, em La Habana, República Socialista de Cuba, e foi defendida no dia 25 de Abril de 2014. 0 mesmo foi elaborado por convite do Director e do Editor desta revista e para os quais expresso os meus mais sinceros agradecimentos. 


\section{Introdução}

\subsection{Fundamentação sobre o problema em estudo}

1 A vida dos indivíduos transcorre e desenvolve-se em um tempo e espaço, sendo determinada por acções e condutas sociais para as quais é necessário uma determinada educação como processo de transmissão de significados sociais duma sociedade, educação essa que permita aos seus membros inserção e participação activas nessa sociedade em que vivem.

2 Hoje em dia, a sociedade humana assiste ao que universalmente tem sido reconhecido como determinada «crise» ou «quebra» de valores, ou, ao menos, pela ruptura de determinadas escalas ou hierarquias de valores, que durante muito tempo tinham sido aceites como estáveis ou pouco questionadas, quando estas não perderam de algum modo credibilidade. $O$ que fazer perante tal situação? Para essa questão não há apenas uma resposta única, já que, em diferentes latitudes, muitas vozes se têm expressado para oferecer propostas de solução para tais problemas: uma delas provém da África, mais concretamente de Angola.

3 A sociedade angolana está em constante processo de mudança; isso inclui necessidades intelectuais e prioridades económicas, sociais, educacionais, entre outras. Como consequência, os pressupostos da educação em valores devem ser analisados segundo uma perspectiva tendente a preparação da população e, em particular, das comunidades conforme determinados postulados educativos, que lhes permitam irem descobrindo as suas capacidades afectivas e sociais.

4 Angola é um país que viveu durante pouco mais de quatro séculos sob as amarras do colonialismo português, sendo esse longo período caracterizado pela transformação da colónia em território fornecedor de matérias-primas e, consequentemente, pela generalização constante de um ambiente de pobreza das suas populações e comunidades, já que, o sistema ignóbil colonial-fascista não teve em conta a formação de recursos humanos autóctones. A somar a essa desgraça, após a proclamação da sua independência, o país sofreu durante quase 30 anos as agruras de um conflito armado guerra civil $^{1}$ - que praticamente impediu o seu desenvolvimento social, económico e cultural.

5 Fruto da estruturação colonial e consequentemente da guerra que se seguiu e praticamente o destruiu, este país continua a ter uma elevada taxa de pobreza em todas as esferas da sociedade, e, paradoxalmente, luta por se impôr como uma sociedade moderna e competitiva. Nessas condições, o encontro entre a tradição e a modernidade pode ser violento se do ponto de vista teórico e prático não for realizada uma condução social adequada. Para isso, afigura-se-nos necessário projectar múltiplos programas que assentem em práticas e saberes que expressem as necessidades das populações e comunidades e indiquem os modos de actuação para satisfazê-las, prevendo os impactos que se devem produzir a curto, médio e longo prazos. Hoje em dia, é nessas transformações comunitárias que se desenvolve a vida espiritual da sociedade angolana, o que faz com que esta esteja necessitada de propiciar uma educação em valores.

6 Consequentemente, desde o passado ao presente e mais concretamente desde o fim da guerra aos nossos dias, se verifica que o problema do resgate dos valores tem constituído um aspecto dominante no discurso dos mais altos líderes da nação. $\mathrm{Na}$ 
primeira fase da vida do país independente, já o primeiro presidente do país, Dr. António Agostinho Neto, numa das entrevistas que terá concedido ao Jornal de Angola, apontaria vigorosamente:

«[...] Não se transforma a consciência de um homem de um momento para outro. É necessário explicar, é necessário transformar a base material. É preciso estar totalmente convencidos com todos os instrumentos nas mãos, para realizarmos essa transformação lenta da consciência de um povo e do nosso país... Vamos elevar na esfera da cultura, a nossa concepção de cultura angolana para que a nação, para que todo nosso povo seja cada vez mais angolano, para que as características nacionais possam ser dominantes em nossa terra» (cf. NETO 1978: 1-2, 6).

7 Tal como Agostinho Neto expressou nessa entrevista, nós entendemos que em Angola a educação em valores constitui uma exigência da sociedade angolana actual, inserida num mundo globalizado e marcada, pelo menos desde o século passado, por grandes mudanças tecnológicas e por novos paradigmas: políticos, económicos, sociais, culturais e educacionais.

Nesta linha de pensamento está o Programa do Governo para o quadriénio 2009-2012 que, na contracapa deste importante documento, transcreve uma máxima do Presidente da República, Eng. . José Eduardo dos Santos, que enfatiza o seguinte:

«[...] Ao aplicarmos este Programa, estaremos a construir no presente o nosso futuro, o futuro dos nossos filhos, na base de um projecto nacional abrangente, que enalteça o orgulho nacional e a auto-estima dos angolanos, proporcionando para todos os cidadãos os mais altos padrões de vida e bem-estar social» (cf. SANTOS apud MPLA 2008).

Para que possam ser efectuados estudos e investigação acerca dos valores na comunidade, é necessário partir de uma abordagem teórica que responda às especificidades das relações sociais baseadas na convivência e determinadas pela forma como as pessoas vivem quotidianamente.

\subsection{A educação em valores e suas bases}

10 O reconhecimento da educação em valores é um aspecto importante para o desenvolvimento da comunidade e este se reflecte cada vez mais no âmbito da investigação científica e em documentos oficiais, tais como, por exemplo, o Relatório Brundtland, um documento da Organização das Nações Unidas (ONU) designado Nosso futuro comum $(1987 ; 1991)$, sobre a sustentabilidade ambiental do planeta Terra; esse reconhecimento aparece igualmente na agenda de fóruns de organizações e organismos internacionais das Nações Unidas (2005), tais como o PNUMA - Programa de Nações Unidas para o Meio Ambiente (2004; 2011); o PNUD — Programa de Nações Unidas para o Desenvolvimento (2013; 2014); no programa da UNESCO - Organização das Nações Unidas para a Educação, a Ciência e a Cultura (1990; 1999; 2007); e, enfim, ele constitui também uma preocupação dos diferentes Estados e governos.

11 Relativamente a Angola, de acordo com algumas fontes e relatórios consultados, dos quais se destacam, por exemplo, o programa da ADPP - Ajuda de desenvolvimento de povo para povo (2009), o Programa Onjila: Educação para o desenvolvimento promovido pela ONG angolana ADRA - Acção para o Desenvolvimento Rural e Ambiente (cf. 2005; SANTOS, SILVA e SILVA 2010; SANTOS, SILVA e CAMBUTA 2011), os programas desenvolvidos pela Odebrecht Angola (2004 e 2008), ou o Programa de formação e desenvolvimento em Angola da Fundação Repsol (2011); ademais, constata-se que a 
partir dos anos 1990 foram surgindo múltiplas inciativas de universidades, líderes comunitários, educadores, entre outros operadores, que começaram a trabalhar nas periferias das cidades e nas zonas rurais; todavia, embora utilizem o diálogo e as técnicas participativas que lhes permitam a constatação e a consequente investigação dos processos para a educação em valores no contexto comunitário, no entanto, os seus resultados ainda são insuficientes.

Neste contexto, observa-se também que há um grupo de sociólogos que têm realizado trabalhos acerca dos valores na sociedade, na qual se evidencia a transição nos valores em dois períodos essenciais: durante as décadas 1980 e 1990 e durante a década de 2000, quando o país entrou na economia de mercado com marcada influência da globalização. Pode-se citar entre os mais importantes, Fátima Viegas (1999), Paulo de Carvalho (2002; 2007) e Víctor Kajibanga (2008).

No entanto, apesar da existência desses trabalhos e estudos, não tem sido desenvolvido uma aproximação teórico-metodológica ancorada em ferramentas científicas apropriadas para aprofundar os processos socioeducativos que contribuam para a mudança dos modos de pensar, de sentir, de valorar e de agir dos cidadãos que residem nos bairros periféricos, em correspondência com a necessidade de se alcançar uma verdadeira participação para o desenvolvimento comunitário.

A sociedade angolana, enquadrada no âmbito de um país subdesenvolvido, está formada fundamentalmente por comunas de múltipla origem social e com enormes e complexas formas de convivência. Esta característica constitui um desafio para o método de investigação, que deve abranger multilateralmente o objecto em sua dinâmica e desenvolvimento, e, ao mesmo tempo, procurar que a sua finalidade seja generalizável.

\subsection{O Bairro Benvindo}

O Bairro Benvindo localiza-se no município de Belas, na comuna Benfica. Uma parte importante deste território formava parte da periferia da actual província de Luanda, e o resto, a área de maior dimensão está encravada na parte rural da capital. Este bairro, apesar de ter sido formado de forma espontânea, tal como outros similares que apareceram aceleradamente como consequência do expressado antes, pelas características sociais e espaciais de sua formação e desenvolvimento, constitui um cenário adequado para o aprofundamento do processo de socialização e da participação social como valor.

No trabalho de exploração inicial que desenvolvemos no Bairro Benvindo, constatamos que no que diz respeito ao comportamento da participação social e à sua significação para o desenvolvimento comunitário, existem limitações resumidas na seguinte situação problemática: No bairro, tanto as instituições como os indivíduos se caracterizam pela falta de educação acerca do significado da verdadeira participação e sua importância para o desenvolvimento da comunidade, aspectos indicados por:

- Uma evidente falta de consenso na hora da tomada de decisões que envolvam todos os moradores;

- Os habitantes não realizam esforços activos para participarem ou proporem iniciativas na melhoria das suas condições de vida;

- Dificuldades na compreensão fundamental das necessidades e dos recursos do bairro, bem como de sua mudança e evolução; 
- Fraquezas na formação e informação de mensagens para a comunidade através da escola, dos meios de comunicação social, das associações populares e dos organismos em seus diferentes níveis;

- Existência de crise na instituição familiar, fundamentalmente nas relações intra-familiares e conflitos intergeracionais;

- Insuficiente sentido de pertença ao bairro, expressado pela indiferença perante os problemas que se defrontam;

- Uma evidente tendência e apego às tradições e valores de cada etnia.

\subsection{Bases teóricas e metodológicas do presente estudo} desenvolvimento, tem estudado entre outros temas a questão e âmbito dos valores. Tanto na filosofia clássica quanto na moderna e até na pós-moderna, podemos encontrar aproximações filosóficas do tema sobre os valores.

21 As concepções acerca da axiologia foram desenvolvidas por J. R. Fabelo (1996, 2001, 2003), e estas revelam a necessidade de se assumir um enfoque multidimensional dos valores, como um fenómeno complexo manifestado em três planos de análise fundamentais, a saber: em primeiro lugar, do ponto de vista sociológico, a concepção acerca da educação em valores refere-se às forças motrizes do funcionamento social, à finalidade das condutas sociais no âmbito social geral, de grupo ou comunidades e sujeitos específicos; em segundo lugar, a ciência psicológica aborda o estudo dos valores fundamentalmente a partir de sua expressão subjectiva, buscando explicação acerca da origem e regularidades do desenvolvimento daquelas formações psíquicas, de sua estrutura e funcionamento, que favorecem a orientação do homem e sua valoração em relação ao mundo que o rodeia; finalmente, do ponto de vista pedagógico, onde se observa que a sociedade está em constante processo de mudança, as necessidades intelectuais e as prioridades deverão atender igualmente as questões sujeitas a mudanças.

Portanto, em consequência disso, os pressupostos da educação em valores devem ser analisados na perspectiva da instrução dos sujeitos, conforme determinados postulados 
educativos, vistos como entes activos, com potencial cognitivo e afectivo, preparados para ir descobrindo suas possibilidades psíquicas, afectivas e sociais, com a ajuda da informação e conduta de todos os adultos envolvidos em sua educação.

\section{A educação no valor participação social. Sua significação para o desenvolvimento comunitário}

23 Participar significa «estar presente em, ser parte de, ser tomado em conta por e para, envolver-se, intervir em, etc. Participar é influir, responsabilizar-se» (GONZALEZ 1989). A participação é um processo que liga necessariamente os sujeitos e os grupos; a participação de alguém em algo relaciona esse alguém com os outros também envolvidos. Ser participante significa ser coagente, cooperante, co-autor, coresponsável.

Cecília Linares (2012: 80), na sua abordagem sobre este assunto, refere que os especialistas do tema, dentre os quais destaca Maritza Montero (1987), Bertha Medina (2002), Joaquím Herrera Flores (2002), Giulietta Fadda Cori (1990), Bordenave Diaz (2012), Ezequiel Ander-Egg (1993), Alfredo Manrique Reyes (2004), Fernando de la Riva (2000), Roberto Dávalos (1997), Miguel Limia (2005) e tantos outros, também coincidem no sentido de considerar a participação social como um processo que se vai construindo paulatinamente pelos sujeitos através das interações e envolvimentos em diferentes situações, mediante a comunicação e a realização de actividades nas quais desdobram os seus recursos pessoais, emoções, sentimentos, afectos e conflitos. Esse processo, constitui a essência da educação no valor participação social.

Entendemos que a análise e a consequente sistematização das reflexões e conceituações da educação em valores fortalece as relações individuais e colectivas dos membros da comunidade, que expressam a significação socialmente positiva de cada membro e de todos para o desenvolvimento comunitário, desenvolvendo a capacidade para estabelecer um projecto social, que permita promover novas redes de comunicação, interesses e apoio mútuo, com o propósito de alcançar determinados objectivos, satisfazer necessidades, resolver problemas ou desempenhar funções sociais relevantes a nível comunitário, contribuindo para o desenvolvimento da comunidade como espaço socializador e resultado da educação no valor participação social, constituindo esse facto a variável principal da investigação.

Colocando-nos na esteira de Maritza Montero (1987), D. Zacus (1988), Giulietta Fadda Cori (1990), Ezequiel Ander-Egg (1993), Sílvia Galeana e José Luis Sainz (2001), Joaquín Alonso Freyre (2004), Miguel Limia (2005) e R. Silva (2006), entendemos que a participação é um processo que vai sendo construído paulatinamente por parte dos sujeitos, através das interacções e envolvimentos em diferentes situações, mediante a comunicação e a realização de actividades nas quais desdobram os seus recursos pessoais, emoções, sentimentos, afectos e conflitos (LINARES 2012: 82).

R. Silva (2006: 63), faz um enfoque da participação social comunitária, que tem sido amplamente utilizado em muitos países como uma ferramenta efectiva no desenvolvimento rápido e sustentável das comunidades envolvidas. Porém, entendemos que o processo de participação social comunitária constitui um assunto que, entre outros, tem sido definido já em diferentes épocas e por diferentes autores (MONTERO 1987; ZACUS 1988; CORI 1990; ANDER-EGGS 1993). Nesta conformidade, 
tendo em conta o que propõem esses autores, R. Silva define como «a atitude que expressa a significação intelectual e afectiva em relação ao envolvimento em projectos colectivos de desenvolvimento social e educacional, na tomada de decisões e na reflexão crítica de temas de carácter público. $\mathrm{Na}$ investigação, a participação é assumida como processo de envolvimento nas decisões da comunidade e como valor quando este envolvimento é assumido como uma significação intelectual e afectiva» (SILVA 2006: 63).

Os critérios dos autores analisados anteriormente, apontam para a necessidade da educação no valor da participação social da comunidade, na tomada de decisões com respeito aos projectos de desenvolvimento e sua respectiva implementação, o qual exige da educação uma consciência crítica para poder exercer uma aç̧ão transformadora, de tal forma que a consciência crítica, a vontade e a acção se transformem nos três passos de um processo profundamente reflexivo. $O$ processo de educação no valor participação social consiste não só em oferecer actividades, mas em oferecer ocasiões específicas e reais para que se participe activamente das decisões nas medidas organizativas e na realização de programas. A função essencial consiste em ajudar tecnicamente a comunidade a organizar-se, utilizando-se para tal os recursos existentes e buscando outros, para que as pessoas aprendam a participarem.

Na sociedade angolana, particularmente na província de Luanda, a participação social como valor ainda não é entendida como uma acção humana, de envolvimento de toda a comunidade com a finalidade de alcançar uma mudança para o bem de todos; geralmente, os integrantes das comunidades se caracterizam pela ausência de uma participação voluntária; apenas algumas «autoridades tradicionais» e «líderes comunitários» conseguem, em determinados momentos, reunir alguns moradores para a análise de alguma problemática surgida, relacionada directamente com conflitos interétnicos, por exemplo; neste sentido, afigura-se-nos necessária uma mudança, na qual todos os agentes socializadores deverão se envolver como num processo participativo, de modo a transformarem essa actividade num dos modelos educativos mais importantes do país.

$30 \mathrm{Na}$ base deste quadro e tendo em atenção o contexto comunitário dos bairros da periferia da cidade de Luanda, definimos a educação no valor participação social como «um processo de educação de toda a comunidade e de cada membro, no qual se exerce uma influência socializante dos agentes de mudança, na base de seus problemas e necessidades, no qual se procura construir significados socialmente positivos sobre a identidade comunitária, a coesão social, a convivência e a responsabilidade, com a finalidade de serem tomadas decisões, solucionar problemas e alcançar uma adequada qualidade de vida e bem-estar individual e colectivo».

31 Apresentamos, em seguida, as dimensões e os indicadores para a análise da variável participação social como valor:

- Identidade comunitária: Refere-se ao facto de se procurar entender a identidade da mesma como a construção social que esta faz no quotidiano, no processo de identificaçãodiferenciação e na designação e assunção do papel em sua relação com outros grupos de referência; Os indicadores dessa dimensão são: a) Conhecimento da história do bairro, das suas tradições e costumes; b) Sentido que tem de seu lugar no sistema de relações sociais da comunidade e significação que consigna para os outros; c) Sentido de pertencer aos grupos onde se convive e participa de forma pessoal e colectiva; d) A identificação pessoal cognoscitiva e emotiva, que o alia aos interesses e problemas de seu meio comunitário. 
- Coesão grupal: a coesão é concebida como uma dimensão do valor participação social, que exige uma unidade entre todos os membros da comunidade, necessária para enfrentar os diferentes problemas que podem obstaculizar o funcionamento adequado deste grupo social. Os indicadores dessa dimensão são: a) Motivos que fizeram com que o sujeito formasse parte do bairro; b) Opinião que têm acerca dos objectivos grupais, das autoridades tradicionais e da administração comunal; c) Satisfação pelo conteúdo de sua actividade dentro do grupo; d) Adaptação dos indivíduos aos diferentes parâmetros grupais; e) Presença de liderança e de estruturas sociais organizativas na comunidade, que, com baixos recursos comunitários, permitam gerir e executar organizadamente.

- A convivência social: Forma-se a partir da participação social nas tarefas da comunidade e no fomento das relações de respeito entre os diferentes membros da comunidade. Os indicadores desta dimensão são: a) Desenvolvimento de interesses e motivações colectivas na realização das actividades sociais do bairro; b) Capacidade para a solução de conflitos no âmbito comunitário; c) Desenvolvimento de uma comunicação interpessoal na comunidade.

- Responsabilidade social: consiste em mostrar o sentido do dever, a obrigação e o compromisso para o cumprimento das principais actividades que se organizem no bairro. Os indicadores desta dimensão são: Compromissos orientados por valores e objectivos comuns; cumprimento das tarefas designadas no bairro; comportamento moral específico conforme as exigências sociais e do bairro em particular.

Existe uma estreita relação entre a educação no valor participação social e o desenvolvimento comunitário. A educação neste valor promove o desenvolvimento comunitário e aumenta a capacidade da população para tratar questões relativas ao desenvolvimento local.

\section{Concepções actuais do desenvolvimento comunitário}

De acordo com Jacques Delors (1995: 103), a Comissão Internacional das Nações Unidas (ONU) define o desenvolvimento humano como o bem-estar geral dos seres humanos. Para que seja alcançado o referido objectivo, essa comissão considera necessária a aplicação da aprendizagem e indica as necessidades básicas de aprendizagem.

Para esse autor, no Relatório da UNESCO sobre a Educação para o século XXI, educação para o desenvolvimento é definida como aquela que deverá permitir que cada pessoa se responsabilize pelo seu destino, com o fim de contribuir para o progresso da sociedade em que vive, baseando-se o desenvolvimento na participação responsável das pessoas e das comunidades (DELORS 1995: 134).

Ao realizar uma análise dos antecedentes do desenvolvimento comunitário, foi possível determinar diferentes momentos, perspectivas e tendências no seu decurso histórico. Neste sentido, o desenvolvimento comunitário foi considerado uma técnica de aç̧ão social focada na melhoria das condições de vida da população, bem como um processo destinado a criar condições de progresso económico e social para toda a comunidade, incluindo a activa participação desta, e uma maior confiança da sua iniciativa (Id., ibid.: 134).

Enquanto conceito, o desenvolvimento comunitário atravessou vários períodos, caracterizados, na opinião dos especialistas, pela incorporação de agentes, agências e organizações nacionais e estrangeiras na coordenação e cooperação dos serviços da 
comunidade. De forma geral, são identificados sete períodos que possibilitam a determinação das suas tendências mais actuais, a saber:

- Na primeira década do século XX, nos Estados Unidos da América (EUA), são organizados os Conselhos de bem-estar da comunidade;

- Nos anos 1920: São criadas as Missões Mexicanas para tentar melhorar as comunidades rurais latino-americanas;

- Nos anos 1940: É formalizado o método de intervenção social;

- Nos anos 1950: a UNESCO, a Organização Internacional do Trabalho (OIT), o Fundo das Nações Unidas para a Alimentação (FAO) e a Organização Mundial da Saúde (OMS), começam a promover Programas de Desenvolvimento Comunitário com vista contribuir para as mudanças necessárias no sistema socioeconómico;

- Nos anos 1960: Surgem os primeiros Programas de Desenvolvimento da Comunidade como instrumentos da acção governamental na Ásia, África e América Latina. São realizados os primeiros estudos sobre a realidade social;

- Nos anos 1970: Surge uma nova versão do desenvolvimento comunitário: os Programas de Promoção Popular, como forma de integrar os marginalizados.

- Nos anos 1980 e 1990: O desenvolvimento comunitário é estendido como forma de mudar o sistema a partir do interior das próprias comunidades. O lema é: «pensa global e age localmente» (VIGOSTKY 1982: 14-16).

Assim, podemos resumir que o desenvolvimento comunitário é o processo que visa fortalecer e aumentar a eficiência das comunidades a longo prazo, melhorando a qualidade de vida da população e permitindo a sua tomada de decisões para um maior controlo de sua vida. Neste sentido, os programas comunitários de desenvolvimento sustentável contribuem a longo prazo para o fortalecimento da viabilidade da comunidade.

Temos observado que nos últimos anos, o Estado angolano tem prestado especial atenção ao desenvolvimento comunitário, visando que a população resolva os seus próprios problemas. Com esse claro objectivo, tem estimulado um conjunto de programas com vista a obtenção de levantamentos participativos em todos os bairros tanto no perímetro urbano quanto no suburbano. No entanto, na prática social, muitos desses programas acabam por ficar no rol das tentativas e projectos, porque permanecem vazios de contextualização e execução imediata.

\section{Proposta de estratégia de educação no valor participação social para o desenvolvimento comunitário do Bairro Benvindo}

Com vista mudar essa tendência, entendemos que é necessário anteceder toda a iniciativa promovendo-se uma ampla investigação nos contextos de base. Foi isso que procuramos fazer no Bairro Benvindo. Do ponto de vista metodológico, começamos por efectuar uma caracterização do contexto em que a investigação foi desenvolvida, fundamentando o paradigma metodológico adoptado, os métodos e técnicas empregados e a apresentação dos principais resultados, determinando as necessidades que justificam a proposta. Aliás, agindo dessa forma, fundamentamos teórica e metodologicamente a estratégia de educação no valor participação social para o desenvolvimento comunitário do Bairro Benvindo, apontando os objectivos, etapas e 
aç̧ões a desenvolver bem como as suas actividades. Por fim, foi apresentada a avaliação qualitativa da estratégia, mediante o critério de peritagem e a avaliação da aplicação parcial da estratégia.

\subsection{Paradigma qualitativo e desenho metodológico da investigação}

Bruyn (1972), Rist (1977), Patton (1978), Guba (1978), Halfpenny (1979), Reichardt e Cook (1979), Spencer e Dale (1979) e Wallen (1996), são geralmente os representantes de algumas das principais ideias que se conhece sobre os fundamentos teóricos e metodológicos relacionados com o paradigma qualitativo. Para aplicar este paradigma, começamos por considerar a importância de assumir uma atitude de observação sem descartar nenhuma informação, despojada de pré-concepções sobre as condições da comunidade e seus habitantes. Neste sentido, deve-se permitir a abertura para o que possa ocorrer no contexto da pesquisa e estudo e a aceitação do que está a acontecer, mesmo sem que esta seja prevista ou esperada. Este paradigma é assumido como um processo de reflexão crítica e autocrítica, de constante avaliação dos resultados, que exige a colaboração de todos e entre todos; essa démarche propicia a obtenção de conhecimentos colectivos susceptíveis de transformar a realidade da comunidade.

41 Assumir este paradigma e suas características, constitui um pilar para adoptar a perspectiva metodológica da investigação, acção, participação, porque, com base nesta perspectiva, o investigador provoca a mudança social, aceitando que os participantes possuam a capacidade de definir os seus próprios problemas e participem na solução dos mesmos.

\section{Análise dos resultados do diagnóstico do estado actual da variável participação social como valor}

Esta análise é realizada a partir do comportamento, das dimensões e indicadores já apresentados. Esta fase apresenta dois momentos importantes. 0 primeiro momento foi inteiramente realizado por nós com base no nosso projecto de investigação; o segundo momento foi realizado de forma participativa e incluiu os principais agentes do bairro. Esta dupla análise permite aprofundar a informação, verificar os dados, determinar as possíveis contradições e articular a informação quantitativa e qualitativa ou participativa. Nesses dois momentos, foram utilizados métodos e técnicas diversas, tais como a observação e a entrevista estruturada ou semi-estruturada, que permitiram constatar o estado da variável educação no valor participação social, com as suas dimensões e indicadores.

O primeiro momento do diagnóstico do bairro, começou com uma observação natural da dinâmica do bairro, nos horários da manhã e da tarde e a aplicação de uma entrevista aberta a grupos da população, bem como a colecta e análise de documentos diversos, tanto na administração comunal quanto na municipal, e com entrevistas abertas e aprofundadas aos informantes-chave.

O segundo momento, realizado de maneira participativa com os principais agentes de mudança e alguns membros do bairro, começou com uma sensibilização, para o qual foram estabelecidos contactos prévios, com vista a preparação e a consciencialização 
dos principais agentes de mudança acerca dos conteúdos, técnicas e ferramentas a utilizar.

Em relação à dimensão identidade comunitária foram constatadas as seguintes potencialidades:

- Disposição da direcção do bairro para promover mudanças, que permitam o processo de formação e desenvolvimento da identidade;

- Reconhecimento, por parte da população adulta, da significação dos principais representantes do bairro;

- Constatação da existência de um mosaico sociocultural composto por etnias diversificadas, com línguas e culturas que enriquecem os padrões de vida do bairro;

- Evidências de estados de orgulho e dignidade de pertencer ao grupo social étnico na base, das formas iniciais de sua formação e desenvolvimento;

- Evidências de boa disposição da comunidade para assumir tarefas que contribuam para o desenvolvimento local.

- Principais dificuldades encontradas:

- Desconhecimento da história do bairro;

- Diversidade de critérios em relação às origens do bairro;

- Evidências de uma forte consciência sobre as etnias de procedência;

- Limitação do grupo social étnico ao sistema de relações sociais;

- Fortalecimento do sentido de pertença ao nível da etnia e não a nível do bairro, um facto que, em determinadas ocasiões, limita o seu óptimo desenvolvimento;

- O facto de muitos dos moradores do bairro não possuírem identificação oficial (por exemplo, Bilhete de Identidade);

- Baixa auto-estima observada em muitos moradores;

- Evidências de baixo nível de consciencialização e representação da realidade social em que vivem;

- Evidências de preparação insuficiente para a identificação de necessidades e problemas, quando, ao serem convocados pelos responsáveis e líderes da comunidade para tratar de determinados problemas, apenas alguns acorrem e participam;

- Insuficiente participação da população na identificação de problemas, potencialidades e tomada de decisões, verificando-se a predominância de agentes externos.

Em relação à dimensão coesão social foram constatadas as seguintes potencialidades:

- A administração moderna convive com a tradicional, existindo o Soba e o $\mathrm{Jango}^{2}$ como elementos que permitem a convivência das diversas etnias;

- Transformação de um assentamento humano para um bairro organizado com uma estrutura social;

- Interesse colectivo por resolver perante as necessidades básicas do bairro;

- Existência de parteiras tradicionais, que desenvolvem o seu trabalho no bairro e estão dispostas a superar-se para fazer da sua actividade um trabalho cada vez mais seguro;

- Respeito pelas autoridades tradicionais do bairro;

- Interesse constante das autoridades religiosas para o desenvolvimento da comunidade e a formação de valores na população;

- Disposição de adaptação a novos parâmetros grupais;

- Manifestação de uma clara satisfação pelo conteúdo das actividades que se realizam no interior de cada grupo étnico;

- Alta motivação das autoridades tradicionais e governamentais para se superar em matéria de direcção, liderança e experiência empírica dos líderes tradicionais. 
- A formação espontânea do bairro por áreas de procedência, sendo estas constituídas por populações que chegaram como emigrantes de outras províncias, motivados pela longa guerra que se travou no país;

- Existência no bairro de multilinguismo, um facto determinado pela presença da Língua Portuguesa e das Línguas Nacionais (Kimbundu, Kikongo, Umbundu, Ngangela, Kwanyama, por exemplo), um facto que limita a comunicação e tende a dividir o interesse comum;

- Constatação de pouca confiança na gestão das autoridades do bairro e da administração comunal;

- Insuficiente coordenação e integração dos actores sociais da comunidade;

- Tendência para a verticalidade e para o parcelamento;

- Constatação de inexistência de integração entre as distintas instituições que compõem a comunidade, sobretudo quando é necessário desenvolver trabalho em equipa, com vista enfrentar os diversos problemas da comunidade;

- Constatação de baixo nível educativo das autoridades tradicionais, que, geralmente, estão encarregues de promover o desenvolvimento do bairro;

- Constatação de que não há geralmente conexão entre o trabalho a ser desenvolvido pelas autoridades tradicionais e aquele que deve ser levado a cabo pelos funcionários da administração comunal que cuidam do bairro.

Em relação à dimensão convivência social foram constatadas as seguintes potencialidades:

- As relações interpessoais manifestadas no bairro expressam, nas suas diversas formas, o reconhecimento do valor humano, o desejo e a necessidade de se estabelecer o convívio através de relações harmoniosas, com vista a solução dos distintos problemas que ocorrem quotidianamente no bairro;

- Constata-se que há vontade para encontrar solução para os distintos conflitos e para a eliminação das tensões que possam existir no bairro;

- Constata-se, da mesma forma, que geralmente as autoridades tradicionais estão presentes e se envolvem directamente na busca para a solução desses problemas e conflitos.

\section{Principais dificuldades encontradas:}

- Constata-se que existem no bairro diversas formas tradicionais de convivência, dentre as quais predominam as relações familiares e as relações de carácter religioso, factos que, em determinadas ocasiões, dificultam, e, às vezes, até impossibilitam a amplitude das relações interpessoais;

- Constata-se que as relações interpessoais fora dos limites da família têm um carácter situacional, e, no âmbito comunitário, os conflitos são geralmente resolvidos em conformidade com os regulamentos de cada etnia.

Em relação à dimensão responsabilidade social foram constatadas as seguintes potencialidades:

- Constata-se que há todo o interesse em exigir-se o cumprimento dos múltiplos deveres e direitos que ligam qualquer indivíduo à comunidade, bem assim como se verifica que há toda capacidade das autoridades tradicionais para exigir dos moradores as consequências dos seus actos que, geralmente, possam afectar ou interferir no desenvolvimento da comunidade. 
Principais dificuldades encontradas:

- Os deveres e direitos determinados pelo Estado angolano não são observados a nível de bairro, nem são conhecidos por parte de todos os moradores;

- Observa-se, a nível geral, apatia e indiferença entre alguns moradores perante os problemas comunitários;

- Observa-se, igualmente, uma evidente falta de iniciativa e dinamismo dos moradores jovens e uma evidente irresponsabilidade pelos actos praticados por estes, factos que acabam por ser resolvidos em conformidade com as normas estabelecidas por cada etnia.

\section{Proposta de estratégia de educação no valor participação social para o desenvolvimento comunitário}

\subsection{Metodologia}

A concepção metodológica parte do paradigma da participação da população comunitária como sujeito social nos processos de transformação e autogestão. Ela procura responder às interrogações de como fazer e como transformar a partir de uma metodologia de acção/participação, de acordo com os interesses e as necessidades da população, como diagnóstico participativo. Entretanto, com a participação e colaboração do bairro, é realizado o diagnóstico participativo sobre a sua realidade e a partir dela, a mesma concebe as acções de auto-desenvolvimento.

A nossa proposta incorpora os principais agentes de mudança do bairro, isto é, os estudantes universitários e os demais actores sociais. A influência destes abrange a Administração Comunal, o Soba, a Comissão de Moradores, a representação da Organização da Mulher Angolana (OMA) no bairro, os representantes do Movimento Popular de Libertação de Angola (MPLA), os chefes de cada etnia e das diferentes denominações religiosas que existem neste contexto.

Em relação às características da estratégia, a nossa démarche coincide com o critério postulado por Ezequiel Ender-Egg, ao considerar que toda estratégia, qualquer que seja o seu âmbito de aplicação, para ser válida, deve cumprir uma série de requisitos e condições: ser coerente com o objectivo que se pretende alcançar; manter uma sequência de acções; as acções compreendidas em cada circunstância devem ser escolhidas ou seleccionadas com ajuda da informação disponível; identificar os recursos disponíveis (humanos, financeiros e materiais); ter em conta a presença, a acção e os interesses de outros sectores sociais que operam no mesmo cenário e que estão ou podem estar interessados em promover ou obstaculizar um programa, projecto ou actividade; maximizar a utilidade esperada e minimizar a perda máxima e maximizar a vantagem mínima e minimizar o contratempo ou dificuldade máxima (cf. ANDER-EGG 2000: 271-272)

Após a sistematização acerca das diferentes posições teóricas e metodológicas sobre a estratégia e tendo em conta os objectivos e problemas desta investigação no contexto angolano, define-se a «estratégia para a educação no valor participação social para o desenvolvimento comunitário do Bairro Benvindo", como o conjunto de acções planificadas para a educação no valor participação social no contexto comunitário angolano, que facilitem a identidade comunitária, a coesão social, a convivência e a responsabilidade tendentes à 
resolução dos problemas que se manifestam sobre o bem-estar psicológico e social dos indivíduos e grupos sociais entre todos os membros, em função do desenvolvimento comunitário.

\subsection{Objectivo geral da estratégia}

O objectivo geral da estratégia é contribuir para o desenvolvimento comunitário do Bairro, que inclua as diferentes áreas da vida social e tenha como meta o pleno desenvolvimento (económico, social, cultural, organizativo, espiritual) dos seus moradores.

\section{Etapas da estratégia de educação no valor participação social para o desenvolvimento comunitário do Bairro Benvindo}

\section{Etapa I - Diagnóstico participativo do Bairro}

Tem por finalidade a busca e o processamento da informação inicial, participativa, a selecção dos agentes da mudança e a determinação das principais necessidades do bairro.

\section{Etapa II - Desenho e planeamento das acções}

Objectiva a determinação dos critérios metodológicos necessários para alcançar os fins, a missão e o desenho das actividades.

Etapa III - Execução e implementação das acções

Efectua a apresentação aos membros do bairro os resultados obtidos e a divulgação dos seus resultados.

Etapa IV - Generalização dos resultados da avaliação final

Efectua a implementação das actividades, a avaliação do cumprimento dos objectivos propostos e a análise de como se solucionaram os problemas detectados no diagnóstico inicial do bairro. Faz a avaliação final das acções da estratégia.

\section{Finalidade:}

Está centrada em se conseguir neste bairro a auto-transformação dos seus membros (moradores), através da participação social comunitária mediante o desenvolvimento dos espaços de reflexão grupal, de participação e identificação dos problemas que constituem as causas de suas dificuldades e potenciem a consciência crítica em torno do tema abordado e que promovam mudanças de atitudes em todos os membros do Bairro.

\section{Resultados:}

Este processo de investigação/acção participativa possibilitou o facto de as pessoas poderem conhecer-se e, através dele, puderem compreender os problemas gerais da comunidade. Levou a que elas pudessem reconhecer os bloqueios em suas vidas ou as formas de conceber os factos da vida quotidiana, para que, desse modo, possam melhorar, evoluir, progredir e se aperfeiçoarem. Assim...

- As actividades foram úteis para pensar e planificar a prática diária;

- Através do interesse despertado pelo conteúdo da actividade, procurou-se que em todos os momentos estas pudessem aprender unicamente, evitando assim que a questão da avaliação, que deveria ser feita posteriormente, pudesse interferir na entrega destas; 
- Nas actividades desenvolvidas, conseguiu-se que os participantes, como sujeitos da investigação, analisassem os valores no interior de si mesmos, de forma que pudessem compreender como fazê-los emergir em todas suas manifestações e actuações diárias;

- Foi conseguida uma comunicação aberta, que procurou a compreensão dos seus problemas, as circunstâncias e suas reacções perante determinadas situações;

- As actividades despertaram a esperança de ver que existem possibilidades de mudança, sem necessidade de se esperar por transformações gerais a nível de todo o país, evitando-se com isso frustrações;

- Ao se adaptarem às actividades do grupo, dividindo os mesmos problemas e preocupações e procurando em conjunto solução para os mesmos problemas, os participantes sentiram na carne o valor da esperança;

- Observaram-se passos discretos na criação de um clima de confiança, segurança, acolhimento, diálogo, afecto e aceitação, situações necessárias à criação de um clima favorável para a mudança;

- A maioria dos presentes compreendeu que o trabalho individual não oferece grandes oportunidades e este apenas encontra o seu esplendor quando as tarefas são compartilhadas, quando há acordos e consensos entre todos moradores do bairro, como forma de dar coerência e qualidade ao que todos oferecem;

- Contribuiu-se, em determinada medida, para a geração de uma visão de futuro;

- Os participantes aprenderam a tomar as suas próprias decisões;

- Um pensamento positivo acabou por ser potenciado em número considerável de participantes;

- Foi favorecida a livre expressão de ideias, facto que ajudou a serem vencidos os medos e inibições;

- A interacção entre participantes de diversas idades, experiências e vivências diferentes, constituiu um factor essencial, possibilitando aos presentes, enquanto pessoas, que se sentissem compreendidas, respeitadas e as suas ideias valorizadas.

Finalmente, foi realizada uma reunião com toda a comunidade, na qual foi explicado todo o processo seguido e foram expostos os resultados do mesmo. Geralmente, este momento coincide com a divulgação de forma generalizada dos resultados. Procurou-se explicar a todos os presentes sobre a importância de se reunirem conforme fora acordado com vista examinar as acções que ainda faltam desenvolver na comunidade, aç̧ões essas que poderão realizar com os seus próprios recursos com vista concretizar as aspirações tendentes a organização comunitária desejada por todos.

Após a reunião efectuada com a comunidade, ficou acordado que se deveria continuar o trabalho de grupo, com vista reflectir sobre as acções a serem implementadas a médio e a longo-prazo, assim como as acções tendentes ao aperfeiçoamento das tarefas já implementadas na base das fraquezas ainda existentes, bem como a gestão externa necessária, com vista o alcance das metas desenhadas. 


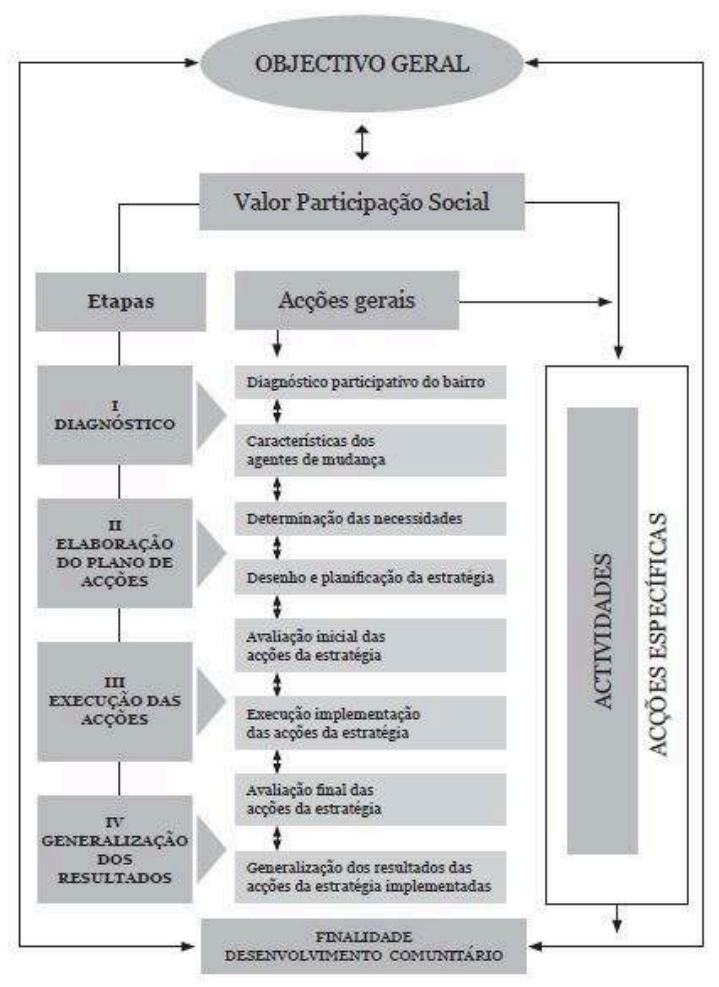

\section{Conclusão}

Os referentes teóricos e metodológicos que fundamentaram a investigação, permitiramnos a assunção de uma concepção que articula enfoques e teorias que sustentam a educação no valor participação social e as suas relações com o desenvolvimento comunitário em comunidades periféricas, do ponto de vista de um processo socioeducativo harmónico de desenvolvimento das comunidades, que exige um envolvimento consciente e responsável de toda a população, as instituições ou organismos competentes da estrutura estatal de base, assumindo as autoridades tradicionais do bairro um inquestionável papel relevante.

o diagnóstico realizado, permitiram-nos constatar que os problemas da participação social da população na comunidade estudada estão, em geral, relacionados ao facto desta não estar preparada para a identificação das suas necessidades e problemas relacionados com a identidade, convivência, coesão e responsabilidade, não constituindo estes aspectos a componente educativa no contexto do bairro; portanto, é reflectida uma afectação significativa no desenvolvimento da variável educação no valor participação social.

A estratégia para a educação no valor participação social no desenvolvimento comunitário foi elaborada a partir da metodologia da investigação e acção participativa; ela permitiu mobilizar a comunidade, construindo significados socialmente positivos sobre a identidade comunitária, a coesão social, a convivência e a responsabilidade, com a intenção de tomar decisões, solucionar problemas e alcançar uma adequada qualidade de vida e bem-estar individual e colectivo. 
Depois de submetida a estratégia aos critérios dos especialistas, e implementadas as aç̧ões a curto prazo, foi o mesmo avaliado como adequado ao seu desenho e implementação, com avanços significativos nas dimensões identidade e coesão social.

\section{BIBLIOGRAFIA}

ABREU Maurício de Almeida, 1986, «O crescimento das periferias urbanas nos países do Terceiro Mundo: uma apresentação do tema», in Milton Santos e Maria Adélia A. Souza (orgs.), A construção do espaço. São Paulo, Nobel, pp. 61-70.

ACCORD, ver MEIJER Guus, infra

ADPP - AJUDA DE DESENVOLVIMENTO DE POVO PARA POVO, 2009, Relatório Anual 2009. Luanda, ADPP, 40p. [www.adpp-angola.org].

ÁGUILA David del, 2006, «El marco lógico como instrumento de gestión y evaluación de proyectos sociales», in Bases conceptuales e instrumentales del monitoreo y evaluación de proyectos sociales. Lima, Pontifícia Universidade Católica do Perú, pp. 171-271.

AGUILAR Maria José, 2001, La participación comunitaria en salud: ¿Mito o realidad?, Madrid, Díaz de Santos.

ALBERTO Maria Adelina Lima do Nascimento, 2014, «La participación social en los asentamientos urbanos de las periferias de Luanda. Importancia para los sujetos emigrados», in Revista Orbita Científica (La Habana), vol. 20, n.ำ 77, Março-Abril, pp, 34-45.

ALBERTO Maria Adelina Lima do Nascimento, 2014, «Estrategia para la educación en el valor participación social para el desarrollo comunitario del barrio Benvindo», in Memorias del Congreso Universidade. La Habana, Palacio de las Convenciones, pp. 88-99.

ALBERTO Maria Adelina Lima do Nascimento, 2013, «Problemática del desarrollo comunitario en Angola a partir del tiempo de paz», Revista IPLAC (La Habana), n.ㅇ 6, Novembro-Dezembro, pp. 76-86.

ALBERTO Maria Adelina Lima do Nascimento, 2013, «Una aproximación a los antecedentes del desarrollo comunitario en el contexto de la sociedad angolana», in Memorias del Congreso de Pedagogía. La Habana, Palacio de la Convenciones, pp.184-195.

ALBERTO Maria Adelina Lima do Nascimento, 2013, «El trabajo social en comunidades periféricas de la capital angolana. Una mirada hacia el futuro", in Lo comunitario en la transformación y emancipación de la sociedad. Santa Clara, Universidad Central Marta Abreu de Las Villas, pp. 12-15.

ALBERTO Maria Adelina Lima do Nascimento, 2012, «Estrategia de la intervención para la educación en valores morales para contribuir al desarrollo comunitario», in Jornada Científica Nacional. La individualización del entrenamiento y el desentrenamiento para garantizar la calidad de vida de los deportistas. Santa Clara, Proyecto CITMA, pp. 959-978.

ALBERTO Maria Adelina Lima do Nascimento, 2010, «Os psicólogos são cada vez mais procurados para o resgate dos valores para o desenvolvimento comunitário», in Factual. Jornal semanal (Luanda), n. 128, pp. 19-20. 
ANDER-EGG Ezequiel, 2002, Metodología y práctica del desarrollo comunitario. Buenos Aires, Editorial Lumen.

ANDER-EGG Ezequiel, 2000, Cómo elaborar un proyecto. Guía para diseñar proyectos sociales y culturales. Buenos Aires/Bogotá, Editorial Humanistas.

ANDER-EGG Ezequiel, 1993, Tecnicas de investigacion social. Bueno Aires, Editorial Lumen. ANDER-EGG Ezequiel, 1982, Metodología del trabajo social. Alicante, Instituto de Ciencias Sociales Aplicadas.

ANGOLA, 2003, Angola. A luta em tempos de paz. O retorno e o reassentamento em Angola, vol. 15, n.․․ 16 (A). Disponível em [www.hrw.org/sites/default/files/reports/angola0803pt.pdf].

ARAMBURU C., 2004, «Visión y misión. Relacionando la idea del proyecto y el grupo ejecutor», in Metodología y técnicas para el monitoreo y evaluación de proyectos sociales. Lima, Pontifícia Universidade Católica del Perú, pp. 784-105.

ARANGO Joaquín, 1985, «Las leyes de las migraciones de E. G. Ravenstein, cien años después», REIS - Revista Española de Investigaciones Sociales (Madrid), n. 32, pp. 7-26.

ASÚN Domingo et al., 1993, «La psicología comunitaria en Chile. Análisis de sus características y perspectivas», in E. Wiesenfeld e E. Sánchez (orgs.). Psicología social comunitaria. Contribuciones latino-americanas. Caracas, Tropykos, pp. 151-188.

AUBEL J., 2000, Manual de evaluación participativa del programa: Involucrando a los participantes del programa en el proceso de evaluación. Madrid, Nueva Imprenta, S.A. [http://www.coregroup.org/ storage/MonitoringEvaluation/PartEvalManual.Spanish.pdf].

BÁXTER Esther, 2002, ¿Cuándo y cómo educar en valores? La Habana, ICCP.

BÁXTER Esther, 1999, «La educación en valores. Papel de la escuela», in Pedagogia 99. Curso 24, La Habana.

BÁXTER Esther, 1990, La orientación en adolescentes y jóvenes. Tesis de doctorado. La Habana, Instituto de Ciencias Pedagogicas.

BÁXTER Esther, 1989, La formación de valores, una tarea pedagógica. La Habana, Editorial Pueblo y Educación.

BRUYN Severyn T., 1972, La perspectiva humana en sociología. Buenos Aires, Amorrortu Editores.

BUCHELI Brenda, 2006, Fundamentación teórica y ética de la evaluación social de proyectos. Material de Trabajo. Lima, Pontificia Universidad Católica del Perú.

BUNGE Mario, 2002, Crisis y reconstrucción de la filosofía. Barcelona, Editorial Gedisa.

BUXARRAIS M. R.; MARTÍNEZ M.; PUIG J. M. e TRILLA J., 1995, La educación moral en primaria y en secundaria. Madrid, Ministerio de Educación y Cultura; Edelvives.

CABANAS J. M. Quintana, 1992, «Educación en valores y diseño curricular», in Perfiles para una nueva educación. Granada, Instituto de Ciencias de la Educación de la Universidad de Granada, pp. $15-26$.

CALDERÓN R.; CORTEZ C. e SOSA A., 2003, Experiencias de enfoques participativos en promoción comunitaria en el Programa de Investigación Interdisciplinario «Desarrollo Humano en Chiapas» de la Universidad Autonoma de México. México, Universidad Autonoma de México. [http:// desarollohumano.xoc.uam.mx]. 
CAMPS V., 1994 (4. a edição), «Los valores de la educación, in Hacer Reforma. Madrid, Alauda, Anaya.

CARDOSO Fernando Henrique, 1978, «Hacia otro desarrollo», in Marc Nerfin (ed.), Hacia otro desarrollo: Enfoque y estrategias. México City, Siglo XXI, pp. 29-48.

CARVALHO Paulo de, 2007, «Até você já não és nada!...» Luanda, Editorial Kilombelombe [«Ciências Humanas e Sociais: série Sociologia e Antropologia»; 4].

CARVALHO Paulo de, 2007, 2002, Angola. Quanto tempo falta para amanhã? Oeiras, Celta Editora.

CARVALHO Ruy Duarte de, 1997, «A propósito do que não se sabe sobre os musseques de Luanda», in Ruy Duarte de Carvalho, A câmara, a escrita e a coisa dita: Fitas, textos e palestras. Luanda, Instituto Nacional do Livro e do Disco, Luanda.

COMISSÃO MUNDIAL SOBRE MEIO AMBIENTE E DESENVOLVIMENTO, 1991 (2. a edição), Nosso Futuro Comum. Rio de Janeiro, Editora da Fundação Getúlio Vargas.

COMMERFORD Michael G., 2005, O rosto pacífico de Angola. Biografia de um processo de paz (1991-2002). Luanda e Windhoek, John Meinert Printing.

CONSTITUIÇÃo, 2010, Constituição da República de Angola. Luanda, Assembleia Nacional, Comissão Constitucional.

CORI Giulietta Fadda, 1990, La participación como encuentro: Discurso político y praxis urbana. Caracas, Universidad Central Venezuela; Fondo Editorial de Acta Venezolana.

CORRÊA R. L., 1989, O espaço urbano. São Paulo, Ética.

CORTÉS Alejandra, 2003, «Implicaciones psicopedagógicas de un desarrollo moral integro: La educación holística», Revista Iberoamericana de Educación [http://www.rieoei.org/deloslectores/ 445Cortes.pdf].

CORZO José Ramón Fabelo, ver FABELO José Ramón, infra

CRISP Jeff; RIERA José e FREITAS Raquel, 2008, Avaliação do programa de reitegração de refufiados do ACNUR em Angola. Genebra, Alto Comissariado das Nações Unidas para os Refugiados; Serviço de Avaliação e Desenvolvimento de Políticas.

CRUZ Fátima, 1999, Psicología comunitaria. Buenos Aires, Editorial Lumen [«Humanitas»].

DÁVALOS Roberto, 1997, Desarrollo urbano: Proyectos y experiencias de trabajo. La Habana, Universidad de La Habana.

DEL ÁGUILA David, ver ÁGUILA David del, supra

DELGADO C., 1986, «Desarrollo y participación», in Socialismo y participación (Lima), n.ำ16, pp 23-33.

DELORS Jacques, 1998, «A educação ou utopia necessária», in Educação: Um tesouro a descobrir. Relatório para a UNESCO da Comissão Internacional sobre Educação para o século XXI. Destaques. Brasília, UNESCO - Representação do Brasil, pp. 5-25.

DELORS Jacques et al., 1996, La educación encierra un tesoro. Informe de la UNESCO de la Comissión Internacional sobre la educación para el siglo XXI, presidida por Jacques Delors. Madrid, Santillana Ediciones; UNESCO.

DELORS Jacques et al., 1998, Educação: Um tesouro a descobrir. Relatório para a UNESCO da Comissão Internacional sobre Educação para o século XXI. Destaques. Tradução de Guilherme João de Freitas Teixeira. Brasília, UNESCO - Representação do Brasil, 43p. 
DELORS Jacques et al., 1998, Educação: Um tesouro a descobrir. Relatório para a UNESCO da Comissão Internacional sobre Educação para o século XXI. São Paulo, Cortez; Brasília, MEC/UNESCO.

DELORS Jacques (org.), 2005, A educação para o século XXI: Questões e perspectivas. Porto Alegre, Artmed.

DÍAZ Bordenave, 1985, Participación y Sociedade. Buenos Aires, Búsqueda.

DÍAZ Cándido Aguilar, 1998, Fortalecimiento de valores: Una necessidad de todos los tiempos. Camagüey, Instituto Superior Pedagógico José Martí.

FABELO José R., 2003, Los valores y sus desafíos actuales, La Habana, Editorial José Martí.

FABELO José R., 2001, «Poder y valores instituidos», in Memoria. Revista mensual de Política y Cultura (México DF), n.ำ144, pp. 29-36.

FABELO José R., 1996, La formación de valores en las nuevas generaciones. La Habana, Editorial Ciencias Sociales.

FABELO José R., 1996, Retos al pensamiento en una época de tránsito. La Habana, Editorial Academia.

FABELO José Ramón et al., 1996, La formación de valores en las nuevas generaciones. Una campaña de espiritualidad y de conciencia. La Habana, Editorial Ciencias Sociales.

FLORES Joaquín Herrera, 2002, Los derechos humanos como productos culturales. Crítica del humanismo abstracto. Madrid, Los Libros de la Catarata.

FREYRE Joaquín Alonso, 2009, La comunidad y lo comunitario en su devenir histórico. Universidad Central Marta Abreu de las Villas, Centro de Estudios Comunitarios.

FREYRE Joaquín Alonso, 2004, El autodesarrollo comunitário. Crítica a las mediaciones sociales recorrentes para la emancipación humana. Santa Clara, Universidad Central Marta Abreu de la Villas e Editorial Feijóo.

FREYRE Joaquín Alonso, 2003, Gestar lo comunitario. Santa Clara, Universidad Central Marta Abreu de la Villas e Editorial Feijóo.

FREYRE Joaquín Alonso et al., 2004, El autodesarrollo comunitario. Crítica a las mediaciones sociales recurrentes para la emacipación humana. Santa Clara, Universidad Central Marta Abreu de Las Villas, Centro de Estudios Comunitarios e Editorial Feijóo.

FUNDAÇÃO REPSOL, 2011, Formação e desenvolvimento em Angola. [http://www.repsol.com/ 28deJuliodell2011], acessado em 14 de Agosto de 2013.

GALEANA Silvia e SAINZ José Luis, 2001, Estrategias de participación social para el desarrollo comunitario. México, Editores Buena Onda, S.A.

GALICIA L. Fernando Arias, 2001, Introducción a la metodología de investigación en ciencias de la administración y del comportamiento: contabilidad, economía, administración, psicología, sociología, trabajo social. México D.F., Trillas.

GARCÍA Jorge L. Tizón et al., 1993, Migraciones y salud mental. Barcelona, Promociones y Publicaciones Universitarias.

GONZALEZ A. Rodriguez, 1989, «Interpretación de las actitudes», in J. Mayor y J. L. Pinillos (eds.), Tratado de Psicologia General. Creencias, actitudes y valores. Madrid, Alhambra.

GONZALEZ A. Rodriguez, 1989, «Interpretación de las actitudes», in A. Rodríguez e J. Seoane, Creencias, actitudes y valores. Madrid, Alhambra. 
GONZALEZ Susana Arteaga, 1999, Propuesta de una estrategia educativa para el trabajo de formación de valores en el nivel medio y superior. Santa Clara, Tesis de Maestría, Instituto Superior Pedagógico Félix Varela.

GUBA E. G. e LINCOLN Y. S., 1978, Effective evaluation: improving the usefulness of evaluation results through responsive and naturalistic approaches. San Francisco, Jossey-Bass.

HALFPENNY Peter, 1979, «The analysis of qualitative data», Sociological Review, vol. 27, n.․ 4, Novembro, pp. 799-825.

HEIDE Aart van der; SMITH Robert e SCHEUERMANN Petra, 2003, Relatório final de avaliação. Avaliação dos Planos Humanitários Globais da Echo em Angola, nomeadamente no que se refere ao tratamento das pessoas deslocadas no interior do país e Avaliação da futura estratégia do Echo em Angola, 10 de Junho de 2002 - 20 de Julho de 2003 [ECHO/EVA/210/2003/01003].

HERNÁNDEZ Ovidio S. d'Angelo, 2004, «Participación y construcción de la personalidad social para una proyección emancipatoria», in Cecilia Linares Fleitas; Pedro Emilio Moras Puig e Yisel Rivero Baxter (orgs.), La participación. Diálogo y debate en el contexto cubano. La Habana, Centro de Investigaciones y Desarollo de la Cultura Cubana Juan Marinello, pp. 221-227.

HERRERA Héctor Arias, 1995, La comunidad y su estudio. La Habana, Editorial Pueblo y Educación.

HUMAN RIGHTS WATCH, 1999 (2.. edição), Angola explicada. Ascensão e queda do proceso de paz de Lusaka. New York, Washington, Londres, Bruxelas, Human Rights Watch.

IDÁNEZ Maria José Aguilar, ver AGUILAR Maria José, supra

KAJIBANGA Víctor, 2008, «Saberes endógenos, ciências sociais e desafios dos países africanos», Revista Angolana de Sociologia (Luanda), n. 2, Dezembro, pp. 7-14.

LIMIA Miguel, 2005, El modo de participación y la reestructuración en Cuba, Informe de investigación. La Habana, Instituto de Filosofía.

LINARES Cecilia, 2012, La Participación. ¿Solución o Problema? La Habana, Centro de Investigación y Desarrollo de la Cultura Cubana Juan Marinello e Editorial José Martí.

MARTín H. San, 1984, Salud comunitaria. Teoría y práctica. Madrid, Díaz de Santos.

MEDINA Bertha Lúcia Cano, 2002, «El aprendizaje de la lectura y escritura en la escuela primaria», impartido a asesores de la mesa técnica federal, Febrero.

[sociedaddospoetasamigos.blogs.com/.../lucia-cano...].

MEIJER Guus (coord.), 2004, Da paz militar à justiça social? O processo de paz angolano. Londres, Accord, n. ${ }^{15}$, 96p. [«Conciliation Resources»].

MINARS - MINISTÉRIO DA ASSISTÊNCIA E REINSERÇÃO SOCIAL, 2006, Relatório sobre o repatriamento voluntário e organizado dos refugiados angolanos, 2002-2005. Luanda, Ministério da Assistência e Reinserção Social.

MONTERO Maritza, 1987, «La psicologia comunitaria: orígenes, princípios y fundamentos teóricos», in S. Barriga, J. M. Léon e M. F. Martínez, Intervención Psicosocial. Barcelona, Hora. MOVIMENTO POPULAR DE LIBERTAÇÃO DE ANGOLA (MPLA), 2008, Programa de Governo para o quadriénio 2009-2012. Luanda, Movimento Popular de Libertação de Angola.

NETO António Agostinho, 1978, «O povo com o seu líder», reportagem de Costa Andrade Ndunduma, Jornal de Angola (Luanda), Ano 3, n. 653, 15 de Janeiro, pp. 1-2, 6.

ODEBRECHT, 2008, Opção pelo futuro. Salvador, Odebrecht S.A., 52p. 
ODEBRECHT ANGOLA, 2008, Balanço social/Social report 2007-2008. Luanda, Odebrecht Angola Projectos e Serviços Ltda., 64p.

ODEBRECHT ANGOLA, 2004, Balanço social/Social report 2004. Luanda, Odebrecht Angola - Projectos e Serviços Ltda., 44p.

ONU — ORGANIZAÇÃO DAS NAÇÕES UNIDAS, 2005, Décadas das Nações Unidas da Educação para o desenvolvimento sustentável, 2005-2014. Documento final; Plano internacional de inmplementação. Brasília.

PASCUAL Alejandra Cortés, ver CORTÉS Alexandra, supra

PATTON Q., 1978, Utilization-focused evaluation. Beverly Hills, Sage.

PÉREZ Esther Báxter, ver BÁXTER Esther, supra

PNUD - PROGRAMA DAS NAÇÕES UNIDAS PARA O DESENVOLVIMENTO, 2013, Relatório do Desenvolvimento Humano 2013. A ascensão do Sul: progresso humano num mundo diversificado.

PNUD - PROGRAMA DAS NAÇÕES UNIDAS PARA O DESENVOLVIMENTO, 2014, Relatório do Desenvolvimento Humano 2014. Sustentar o progresso humano: Reduzir as vulnerabilidades e reforçar a resilência.

PNUMA — PROGRAMA DAS NAÇÕES UNIDAS PARA O MEIO-AMBIENTE, 2004, UNEP/DPDL/WAVE/2. Outubro.

PNUMA — PROGRAMA DAS NAÇÕES UNIDAS PARA O MEIO-AMBIENTE, 2011, Rumo a uma economia verde: Caminhos para o desenvolvimento sustentável e a erradicação da pobreza. Síntese para tomadores de decisão. Prefácio de Achim Steiner. PNUMA - Programa das Nações Unidas para o Meio Ambiente, 44p. Disponível em [http://www.unep.org/greeneconomy/Portals/88/ document/ger/GER_synthesis_pt.pdf].

RATHSL E., HARMIN M.Y e SIMON S. B., 1967, El sentido de los valores y la enseñanza. Cómo emplear losvalores en el salón de clase. México, Unión Tipográfica Editorial Hispano-Americana (UTEHA).

REICHARDT C. R. e COOK T. D., 1979, «Hacia una superación del enfrentamiento entre los métodos cualitativos y cuantitativos», in T. D. Cook e C. R. Reichard (eds.). Métodos cualitativos y cuantitativos en investigación evaluativa. Madrid, Morata.

RELATÓRIO BRUNDTLAND, Nosso Futuro Comum, ver Comissão Mundial sobre Meio Ambiente e Desenvolvimento, supra.

REYES Alfredo Manrique, 2004, Fundamentos de la organización y del funcionamento de Estado Colombiano. Bogotá, Universidad de Rosario; Biblioteca Jurídica Dike.

RIST R., 1977, «On the relations among educational research paradigms: From disdain to detente», Anthropology and Education Quarterly, vol. 22, n.ำ157, pp. 42-49.

RIVA Fernando de la, 2000, «Equipo claves, gestión participativa de los asociados», in Nidia R. González e F. Díaz Argelia (coords.), Selección de lecturas sobre trabajo comunitario. La Habana, Centro de Intercambio Educacional Graciela Bustillos e Associación de Pedagogos de Cuba, pp. $10-18$.

SALCEDO Regla A. Sierra, 2002, «Modelación y estrategia: Algunas consideraciones desde una perspectiva pedagógica», in Compendio de Pedagogía. La Habana, Pueblo y Educacion, pp. 311-328. SANTOS José Eduardo dos, ver MPLA — Movimento Popular de Libertação de Angola, supra 
SANTOS Júlio Gonçalves dos; SILVA Rui da e SILVA Rosa, 2011, «10 anos de cooperação em educação - Actores, contextos e diálogo", in COOP EDU - Congresso Portugal e os PALOP: Cooperação na área da Educação, Livro de Actas. Lisboa, ISCTE - IUL, pp. 125-134.

SANTOS Júlio Gonçalves dos; SILVA Rui da e CAMBUTA Carlos, 2010, «Sociedade civil e educação: a experiência de trabalho em ONGs em Angola», in 7.. Congresso Ibérico de Estudos Africanos, Lisboa.

SILVA R., 2006, Modelo pedagógico para la formación ciudadana del Maestro Primario. Tesis en opción al grado científico de Doctor en Ciencias Pedagógicas. La Habana, Instituto Superior Pedagógico Enrique José Varona.

SOUZA Fátima Cruz, ver CRUZ Fátima, supra

SPENCER M. e DALE A., 1979, «Integration and regulation in organizations: A contextual approach», Sociological Review, vol. 27, n. 4, pp. 679-702.

UNCTAD - CONFERÊNCIA DAS NAÇÕES UNIDAS SOBRE COMÉRCIO E DESENVOLVIMENTO, Quen se beneficia com a liberalização do comércio em Angola? Uma perspectiva de gênero [unctad.org/en/ PublicationChapters/ditc2013d3_pr.pdf].

UNESCO — ORGANIZAÇÃO DAS NAÇÕES UNIDAS PARA A EDUCAÇ̃̃O, A CIÊNCIA E A CULTURA, 1990, Declaração Mundial sobre Educação para todos. Satisfação das necessidades básicas de aprendizagem, aprobada pela Conferência Mundial sobre Educação para todos, Jomtien, Tailândia, 5 a 9 de Março de 1990. Brasília, UNESCO. Disponível em [http://unesdoc.unesco.org/images/ 0008/000862/086291por.pdf].

UNESCO — ORGANIZAÇÃO DAS NAÇÕES UNIDAS PARA A EDUCAÇÃO, A CIÊNCIA E A CULTURA, 1990, Declaración Mundial sobre Educación para todos. La satisfacción de las necesidades básicas de aprendizaje. Jomtien, Tailandia, 5 a 9 de Marzo de 1990. Disponível em [http://www.unesco.el/ medios/biblioteca/documentos/ept_jomtien_declaracion_mundial.pdf].

UNESCO — ORGANIZAÇÃO DAS NAÇÕES UNIDAS PARA A EDUCAÇÃO, A CIÊNCIA E A CULTURA, 1999, XXVII Conferência Mundial sobre o Ensino Superior. Tendências da Educação Superior para o século XXI, Paris, 1998, Anais. Brasília, UNESCO, CRUB.

UNESCO — ORGANIZAÇÃO DAS NAÇÕES UNIDAS PARA A EDUCAÇÃO, A CIÊNCIA E A CULTURA, 1999, Política de mudança e desenvolvimento no ensino superior. Rio de Janeiro, Garamond.

UNESCO — ORGANIZAÇÃO DAS NAÇÕES UNIDAS PARA A EDUCAÇÃO, A CIÊNCIA E A CULTURA, 2007, A UNESCO e a Educação. Disponível em [http://www.unesco.org].

URÍA Fernando Álvarez, 1995, «En torno a la crisis de los modelos de intervención social», in Fernando Álvarez Uría et al., Desigualdad y pobreza hoy. Madrid, Talasa, pp. 5-39. [http:// www.catedras.fsoc.uba.ar/heler/uriaalvares.htm].

VÁSQUEZ Adolfo Sánchez, 1989, Ética. México, Editorial Grijalbo.

VIDAL Alipio Sanchez, 1991 (2. edição), Psicologia comunitaria. Bases conceptuales y operativas. Método de investigación. Barcelona, Editorial Promociones y Publicaciones Universitarias.

VIEGAS Fátima, 1999, Angola e as religiões: Uma visão social. Luanda, Lito Tipo.

VIGOTSKY Lev Semionovich, 1987, Historia del desarrollo de las funciones psíquicas superiores. La Habana, Editorial Científico Técnica.

VIGOTSKY Lev Semionovich, 1982, Pensamiento y lenguaje. La Habana, Editorial Pueblo y Educación.

VILA-BELDA Arango Joaquín, ver ARANGO Joaquín, supra 
WALLEN M., 1996, Técnicas cualitativas de investigación social. Reflexión metodológica y práctica profesional. Madrid, Síntesis.

ZACUS D., 1988, «La participación comunitaria en los programas de atención primaria a la salud en el tercer mundo», Revista de Salud Pública (La Habana), vol. II, n.ํㅜ 6, Editorial Ciencias Médicas, p. 15-45.

\section{NOTAS}

1. A guerra civil em Angola foi um enfrentamento militar, que ocorreu depois da luta armada de libertação nacional, que levou à independência do país e que durou vinte e sete anos; os principais opositores foram o Movimento Popular de Libertação de Angola (MPLA) e a União Nacional para a Independência Total de Angola (UNITA). Durante esse período, as populações oriundas de todas as regiões do interior do país, procuraram conseguir alguma estabilidade social, pelo que viram-se obrigadas a fugir e se refugiar nas zonas limítrofes das sedes de província e principalmente em Luanda, a capital do país; deste modo, produziu-se uma emigração motivada pela guerra. A guerra terminou oficialmente no ano $2002 \mathrm{com}$ a morte de Jonas Savimbi, o líder da UNITA. Mas o conflito armado, cruel e atroz, fez cerca de 500.000 mortos e foi considerado como um dos conflitos mais prolongados ocorrido durante o período da Guerra Fria. Ainda que parciais, existem algumas abordagens sobre a natureza da guerra (cf. por exemplo ACCORD/MEIJER, coord., 2004; CARVALHO 2007; COMMERFORD 2005), e acerca das populações refugiadas e das tentativas para a resolução de suas vidas (cf. ANGOLA 2003; CARVALHO 2007; COMMERFORD 2005; CRISP et al, 2008; HEIDE et al., 2003; HUMAN RIGHTS WATCH 1999; MINARS 2006).

2. O Jango é uma espécie de construção tradicional que serve de ponto de reunião para a organização tradicional. Quanto ao Soba, é um título popular de «chefe» tradicional mais ou menos disseminado por todo o país. Ele se reúne com a comunidade no Jango em momentos transcendentais para a população, sejam eles positivos ou negativos. Para se entrar no Jango é necessário cumprir alguns rituais, geralmente de respeito às autoridades tradicionais.

\section{RESUMOS}

Nos nossos dias, a problemática dos valores humanos constitui um oportuno objectivo de interesses no estudo dos seus mais diversos elementos da estrutura da sociedade. No seu processo de desenvolvimento em Angola, o trabalho da educação em valores tem apresentado múltiplas dificuldades e limitações nos enfoques e práticas da sua gestão, o qual se comprova pelo diagnóstico que efectuamos. Trabalhar com e a partir da comunidade, constitui uma oportunidade e ao mesmo tempo uma exigência porque permite repensar este espaço social fundamental para o trabalho social. Para essa direcção encaminha-se o resultado da presente investigação, que consiste na proposta de uma estratégia para a educação no valor participação social para o desenvolvimento comunitário do Bairro Benvindo, situado na zona sul da periferia da cidade de Luanda; ela tem por fim superar tanto no plano teórico quanto prático, o modelo predominante de intervenção em prol da participação social comunitária, baseado no diálogo e na consciência crítica. $O$ presente trabalho apresenta em primeiro lugar os resultados do 
diagnóstico inicial e a avaliação por critério de perícia, que comprovou a sua pertinência a partir dos pressupostos teóricos e metodológicos da educação no valor participação social para transformação social, em benefício desta realidade, e, em segundo lugar, a avaliação mediante a implementação parcial das acções a curto prazo previstas pela investigação.

The problem of human values is an appropriate object of interest in the study of the various elements of the structure of society. In its development process in Angola, the education for values has presented many difficulties and limitations in both approaches as in the practices of its management. This is revealed by the diagnosis we have made. Working with the community and from the community is an opportunity. But it is also a requirement, because it allows rethink the community as a key area for social work. This research is the proposal of a strategy for education in the value of social participation and community development in Benvindo neighborhood, located in southern Luanda. Its aims to overcome, both in theoretical and practical levels, the predominant model of intervention in favor of Community social participation. First, this paper presents results of the initial diagnosis and, secondly, the assessment by partial implementation of short-term actions envisaged by the investigation.

\section{ÍNDICE}

Palavras-chave: estratégia para educação, valor, participação social, comunidade, desenvolvimento comunitário

Keywords: strategy for education, value, social participation, community, community development

\section{AUTOR}

\section{MARIA ADELINA LIMA DO NASCIMENTO ALBERTO}

linaalberton@hotmail.com

Assistente do Departamento de Psicologia da Faculdade de Ciências Sociais (FCS) da Universidade Agostinho Neto (UAN).

É doutorada em Ciências Pedagógicas (2014) pela Universidade de Ciências Pedagógicas Enrique José Varona, La Habana, República Socialista de Cuba, tendo apresentado a tese intitulada Educação em valor participação social para o desenvolvimento comunitário do Bairro Benvindo, Luanda, Angola; é Mestre em Psicologia do desenvolvimento pessoal e intervenção social (2007), pela Universidade de Valência, Valência, Espanha, tendo apresentado a dissertação $O$ alcoolismo nos adolescentes no Município de Cacuaco, e Licenciada em ensino, opção Psicologia (2003), pelo Instituto Superior de Ciências de Educação (ISCED) de Luanda, tendo submetido o trabalho de fim do curso intitulado A delinquência juvenil no Município de Cacuaco. É Assistente do Departamento de Psicologia da Faculdade de Ciências Sociais (FCS), da Universidade Agostinho Neto (UAN), onde orienta as disciplinas de Introdução à Psicologia Geral, Psicologia do Desenvolvimento, Ética e deontologia profissional. As suas áreas principais de investigação estão direccionadas para questões no âmbito da psicopedagogia e educação, em particular a educação dos valores e intervenção social nas comunidades periféricas de Luanda. Está enquadrada como investigadora nos projectos do Centro de Estudos Comunitarios da Universidad Central Marta Abreu de Las Villas e da Editorial Feijóo, em Santa Clara; está igualmente enquadrada nos projectos de estudos sobre valores do Centro de Estudos dos Valores da Universidade Pedagógica Henrique José Varona, Havana, ambas na República Socialista de Cuba. Publicou os artigos e 
comunicações em revistas e em livros colectivos seguintes: La participación social en los asentamientos urbanos de las periferias de Luanda. Importancia para los sujetos emigrados (2014); Estrategia para la educación en el valor participación social para el desarrollo comunitario del barrio Benvindo (2014); Problemática del desarrollo comunitario en Angola a partir del tiempo de paz (2013); Una aproximación a los antecedentes del desarrollo comunitario en el contexto de la sociedad angolana (2013); El trabajo social en comunidades periféricas de la capital angolana. Una mirada hacia el futuro (2013); Estrategia de la intervención para la educación en valores morales para contribuir al desarrollo comunitario (2012); Os psicólogos são cada vez mais procurados para o resgate dos valores para o desenvolvimento comunitário (2010). 